\title{
Fitness consequences of prey depletion for the common goby Pomatoschistus microps
}

\author{
Angus C. Jackson*, Simon D. Rundle, Martin J. Attrill \\ School of Biological Sciences, University of Plymouth, Drake Circus, Plymouth PL4 8AA, United Kingdom
}

\begin{abstract}
Pomatoschistus microps (Pisces: Gobiidae), a predatory, benthic feeder, occurs in high densities in variable, shallow, muddy coastal waters where prey availability can be unpredictable. Here, we investigate the effect and consequences of prey depletion on the body condition and nest building of adult male fish using manipulative mesocosm experiments in which the comparative value of meiofaunal and macrofaunal prey was investigated. Fish maintained in mesocosms from which macrofauna had been removed from the sediment had a significantly reduced hepatosomatic index (HSI), and were less likely to build nests than fish in mesocosms containing macrofauna and meiofauna, suggesting an indirect link between prey availability and nest quality. Reduced resource availability, in the form of scarcity of macrofauna, appears to have profound implications for the fitness of natural field populations.
\end{abstract}

KEY WORDS: Prey depletion · Feeding behaviour - Pomatoschistus microps · Goby · Mesocosm

\section{INTRODUCTION}

Shallow coastal waters, including estuaries, are environments that often exhibit high variability in biotic and abiotic (e.g. temperature, salinity and $\mathrm{pH}$ ) factors that can lead to inconsistent degrees of reproduction, recruitment, production, predation and competition. Predators in such environments are highly likely to be able to feed on different prey types (Komers 1997) as the abundance of prey populations may vary dramatically (Möller \& Rosenberg 1982, Jensen \& Andre 1993).

The prey of benthic-feeding fish in such systems fall into 2 distinct size classes: the meiofauna (63 $\mu \mathrm{m}<\chi<$ $0.5 \mathrm{~mm}$ ) and macrofauna (>0.5 mm) (Warwick 1984). Where such predatory fish show large ontogenetic increases in size, the potential to shift from small to large-bodied prey is high (Ivlev 1961, Schoener 1971, Stephens \& Krebs 1986) and several fish show ontogenetic changes in diet, relying initially on meiofauna

*E-mail: a.jackson@plymouth.ac.uk before shifting to macrofauna (Bodiou \& Villiers 1979, Evans 1984, Doornbos \& Twisk 1987, Del NorteCampos \& Temming 1994, Aarnio 2001). For some species, these shifts are not fixed in terms of timing, duration or degree (Grossman 1980, Pihl \& Rosenberg 1982, Werner \& Gilliam 1984, Hjelm et al. 2000), suggesting an adaptive response to fluctuations in prey availability. Of most significance is the potential for low or failed recruitment of macrofaunal prey species, where a reversion to feeding primarily on meiofauna would be a valuable alternative strategy. Such reversions may be predictable but should incur a cost (Ebenman 1992, Komers 1997). For example, available biomass may be greatly reduced, energy expenditure for foraging increased, exposure to predation risk increase or reproductive ability may become impaired. Predictions of niche shifts and their consequences have been explored theoretically (Grossman 1980, Werner \& Gilliam 1984, Persson 1990) but few studies provide empirical evidence for the ecological consequences of ontogenetic shifts in diet in benthic predatory fish (but see Olson 1996). 
Gobies are common, often highly abundant, benthic predators in shallow coastal waters (Pihl \& Rosenberg 1982, Miller 1986) where they exhibit highly flexible behaviours in feeding, habitat choice and reproductive tactics in response to abiotic and biotic variability (Edlund \& Magnhagen 1981, Magnhagen \& Wiederholm 1982a,b, Magnhagen 1986, 1988, 1992). Here, we assess the consequences of resource (macrofauna) depletion for the fitness of male common gobies Pomatoschistus microps (Pisces: Gobiidae) by manipulating prey assemblages in laboratory trials.

\section{MATERIALS AND METHODS}

General experimental procedure. This study was carried out during July and August 2001 at the Kristineberg Marine Research Station (KMRS) in the Gullmar Fjord on the Swedish west coast. We used manipulated benthic prey assemblages in mesocosms to investigate the consequences of prey availability for male gobies. Male fish were maintained in mesocosm treatments representing 'natural' sediment, sediment from which macrofauna had been removed and a sediment control for the macrofauna removal procedure (see below). The removal of macrofauna mimicked natural variation in prey availability in shallow bays of the Gullmar Fjord that can occur due to failure in macrofauna recruitment (Möller \& Rosenberg 1982). Such variation in prey availability may alter feeding behaviour (i.e. a shift back to meiofauna) resulting in differential fitness.

We used fish of 30 to $35 \mathrm{~mm}$ standard length (SL), a size that feeds in the field primarily on macrofauna, but also meiofauna; a pilot study demonstrated that fish fed on the available fauna under the experimental conditions. The condition status of fish was assessed after being maintained in experimental mesocosms for $2 \mathrm{wk}$.

Many studies that aim to assess the implications of trait shifts simply assume that a chosen strategy is optimal, and do not incorporate a direct measure of fitness. Here, we use mature adult males as an ideal experimental animal for assessing fitness, recording 2 commonly used measures of body condition. In addition, we use nest building ability, a male character under both natural and sexual selection (Jones \& Reynolds 1999), as a more direct measure of fitness.

Experimental animals: collection and preparation. Mature adult male fish were collected using a $1 \mathrm{~m}$ push-net with a $2 \mathrm{~mm}$ mesh collecting bag from a shallow, muddy inlet on the south side of the fjord (near Dragsmark) where they occurred in high densities. Fish length was standardised at between 30 and $35 \mathrm{~mm}$ in order to reduce size-dependent influence on feeding and nesting behaviour. The mesocosm system consisted of twelve $90 \mathrm{l}$ black plastic containers (circular, $50 \mathrm{~cm} \varnothing, 40 \mathrm{~cm}$ deep) containing sediment (see below) and $\sim 601$ of continuously flowing water abstracted from the surface of the fjord $\left(17\right.$ to $24^{\circ} \mathrm{C}$ and 18 to 25 PSU). Sediment was collected using cores (10 $\mathrm{cm} \varnothing, 4 \mathrm{~cm}$ depth) from the shallow, sandy Finnsbo bay on the north side of the fjord. Core locations (16 per mesocosm) were randomly selected from an homogeneous area of sediment. Experiments were conducted under artificial light approximating ambient conditions (i.e. 19:5 h light:dark cycle). Mesocosms were left to settle and establish for $24 \mathrm{~h}$ before introducing fish; fish were kept in a holding tank for at least $48 \mathrm{~h}$ before introduction to the mesocosms and fed chopped mussel Mytilus edulis.

There were 3 sediment treatment types, each replicated 4 times: 'Macrofauna removal' —-sediment cores were washed through a $0.5 \mathrm{~mm}$ sieve into the mesocosm and macrofauna discarded; 'Sieve control' sediment cores were washed through a $0.5 \mathrm{~mm}$ sieve into the mesocosm, and macrofauna were then returned to the sediment; and 'Untreated' - 16 loaded sediment corers were placed adjacently in each mesocosm in the field, with corer tubes being removed only on return to the laboratory, thus minimising disturbance of the sediment. Using 16 cores per mesocosm gave faunal abundances only slightly less than in the natural environment.

At the start of the experiment, 4 fish were added to each mesocosm giving a density of 20 fish $\mathrm{m}^{-2}$, comparable to densities observed in the field (Pihl \& Rosenberg 1982, Doornbos \& Twisk 1987). The experiment was duplicated to provide replication through time and each ran for $2 \mathrm{wk}$, during which time any fish that showed signs of stress or disease were removed and not replaced. Diseased fish were sacrificed by overdose of anaesthetic (MS222). Where possible, stomach contents of these fish were examined to note the presence of feeding. On termination of the feeding experiment and nest building assessment, fish were sacrificed, as above, before fixation in $4 \%$ buffered formaldehyde.

Prey availability. Prey abundance was measured at the start and end of experiments using 1 sediment core (35 $\mathrm{mm} \varnothing$ ) from each mesocosm. Macrofauna were removed by sieving onto a $0.5 \mathrm{~mm}$ mesh and meiofauna were extracted using Ludox solution (Somerfield \& Warwick 1996). Samples were fixed in $4 \%$ buffered formaldehyde and stored in $70 \%$ alcohol. Fauna were sub-sampled where appropriate before being identified to a major group and enumerated. Initial available biomass between treatments, for the main prey types, was calculated as ash-free dry weight (AFDW), using mean prey sizes from the mesocosms along with published values of length:mass relationships, specific 
gravity, wet:dry weight and dry:AFDW ratios (Warwick 1984, Doornbos \& Twisk 1987). Total initial macrofaunal biomass was estimated for each treatment by adding the Corophium AFDW removed by the fish to the macrofaunal AFDW remaining at the end. The remaining AFDW was measured using a standard weight-loss on combustion procedure (Holme \& MacIntyre 1984).

Two-way ANOVA and post hoc pair-wise comparisons (SNK test) were used to test for differences in prey availability and biomass between dates and treatments. Where required (Cochran's test), data were first square-root $(x+1)$ transformed to achieve homogeneity of variance.

Fish condition measures. At the end of the experiments, fish condition was measured in 2 ways:

$$
\text { Hepatosomatic index: HSI }=\frac{1}{b} \times 100
$$

where 1 was the wet weight of liver (mg) and $b$ was wet body weight minus liver (mg) (Weatherley 1972).

$$
\text { Condition factor: } k=\frac{100000 \times W}{L^{3}}
$$

where $W$ was wet weight $(\mathrm{mg})$ and $L$ was standard length (mm) (Weatherley 1972).

Standard lengths were measured to the nearest $\mathrm{mm}$ using Vernier callipers and weights to the nearest $\mathrm{mg}$ using a top pan balance. Condition indices are frequently used as an indication of the well-being of fish. The 2 measures used here, HSI and condition factor $(k)$, are suitable since they are less dependent on maturity or reproductive status than other indices (e.g. Gonadosomatic index). All between-treatment comparisons for fish condition used a 3-factor, mixedmodel analysis of variance (See Table 1).

Measurement of nest-building. Male common gobies provide all parental care, consisting of nest construction and care of the eggs until hatching. Quality of nest construction may vary considerably, and this character has been previously used in experiments on goby reproduction (Jones \& Reynolds 1999). Fish were

Table 1. Pomatoschistus microps. Analysis of variance for differences in common

\begin{tabular}{|c|c|c|c|c|c|}
\hline Source & $\mathrm{df}$ & SS & MS & $F$ & $\mathrm{p}$ \\
\hline Date & 1 & 6.23 & 6.23 & 5.26 & 0.034 \\
\hline Treatment & 2 & 22.76 & 11.38 & 9.61 & 0.001 \\
\hline Mesocosm (Date $\times$ Treatment) & 18 & 21.32 & 1.18 & 1.57 & 0.150 \\
\hline Date $\times$ Treatment $^{\mathrm{a}}$ & 2 & 2.46 & 1.23 & 1.04 & 0.374 \\
\hline Residual & 24 & 18.12 & 0.76 & & \\
\hline Total & 47 & 70.88 & & & \\
\hline
\end{tabular}
goby hepatosomatic index arising from macrofaunal prey depletion maintained individually in visually isolated $22 \mathrm{l}$ glass tanks furnished with ca. $2 \mathrm{~cm}$ sieved muddy sand, half a ceramic flowerpot ( $4 \mathrm{~cm} \varnothing$ ), and continuously flowing surface water under a 19:5 h light:dark regime. The flowerpot, placed on its side, was used as an analogue of the bivalve shell that would be used for nest building in the natural environment (Magnhagen 1992). Nest construction was assessed after $24 \mathrm{~h}$, previous studies having shown that most nest building males will have completed construction after this time (Magnhagen 1992, Jones \& Reynolds 1999). Nest building was also assessed in a sample of 28 reference fish, removed directly from the natural environment. We followed a standard method to assess nest quality (Kvarnemo et al. 1998) focussing on nest coverage with sand as the most important fitness correlate for which we measured 2 parameters.

Complete nest roof coverage: For each treatment, the ratio of nests with (i.e. the whole of the flowerpot covered with sediment) and without roofs was recorded. Nest building probability in reference fish was used to generate an extrinsic hypothesis against which the ratio of roofs:no roofs for each treatment was compared by calculating exact binomial probabilities for the observed differences. Low expected values made the use of other frequency analyses such as chisquare or G-tests inappropriate (Sokal \& Rohlf 1995).

Nest entrance diameter: On completion of nest construction, entrance diameter was measured to the nearest $\mathrm{mm}$ at the widest point. As with fish condition, a 3-factor, mixed-model analysis of variance was used in between-treatment comparisons of nest entrance diameter.

Nest quality determinants. To investigate potential causal factors for differences in the nest-building activity of individual fish, we compared mean body length and condition (using 1-tailed $t$-tests) between fish that covered nest roofs and those that did not. Body size has been hypothesised as a major factor affecting likelihood of nest construction (Magnhagen 1992) and nest quality may be a predictor of fish condition (Kvarnemo et al. 1998). Linear regression was used to investigate whether length and condition were likely to be factors in determining nest entrance diameter. The $t$-tests were 1 -tailed since nests with covered roofs were considered more likely to have been built by larger and better condition fish. All analyses of variance were carried out using the programme GMAV5. The $t$-tests and linear regressions were conducted in Minitab ${ }^{\mathrm{TM}}$ v.13 and binomial probabilities were calculated using Microsoft Excel. 
(a)

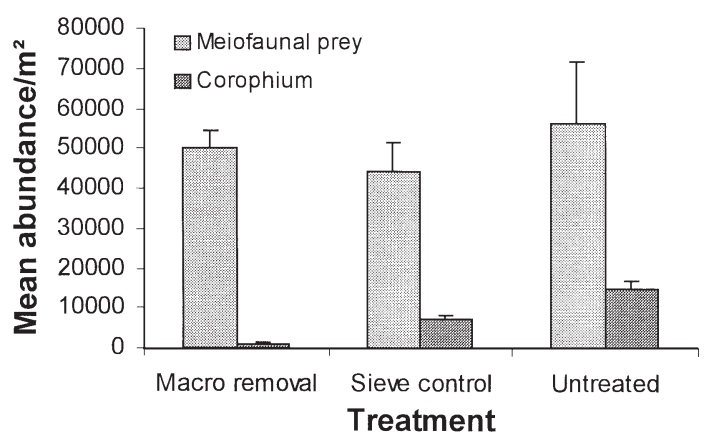

(b)

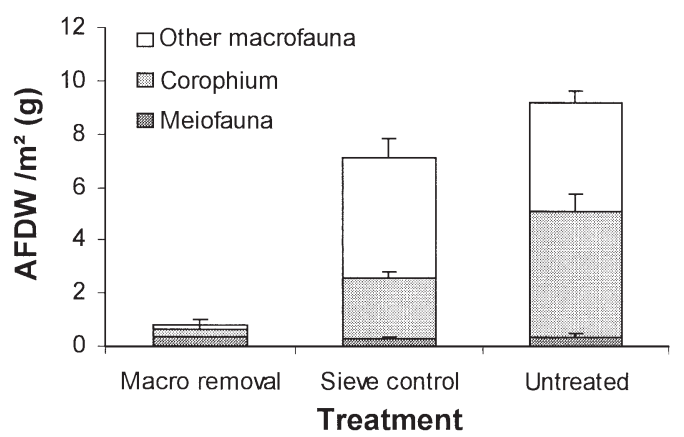

Fig. 1. Pomatoschistus microps. Mean abundance and biomass of available prey with sediment treatment (macrofauna removal, sieve control and untreated). (a) Mean meiofaunal (Copepoda and Ostracoda) and macrofaunal (Corophium) abundance per $\mathrm{m}^{2}$ $(+\mathrm{SE})$ showing no differences in meiofaunal abundance but a significant reduction in Corophium abundance (ANOVA, $\mathrm{p}<0.001)$ and (b) mean prey biomass (g AFDW) (+SE) (meiofauna, Corophium and other macrofauna) with treatment

\section{RESULTS}

Several fish showed signs of disease during the feeding trials and were removed from the mesocosms. To maintain a balanced design, 2 fish from each mesocosm were used in subsequent analyses, giving 8 replicate fish per treatment from each experiment.

\section{Fish diets and initial prey abundances}

Stomach content analysis from the pilot study and diseased individuals indicated that in fish from macrofauna removal mesocosms, $83 \%$ had eaten meiofauna (Copepoda and Ostracoda). From mesocosms with macrofauna, $82 \%$ had eaten Corophium and $36 \%$ meiofauna.

There were no differences between date or treatment in initial meiofauna prey abundance $\left(F_{1,12}=0.12\right.$, $\mathrm{p}>0.05, F_{2,2}=0.21, \mathrm{p}>0.05$, respectively; Fig. 1a) or

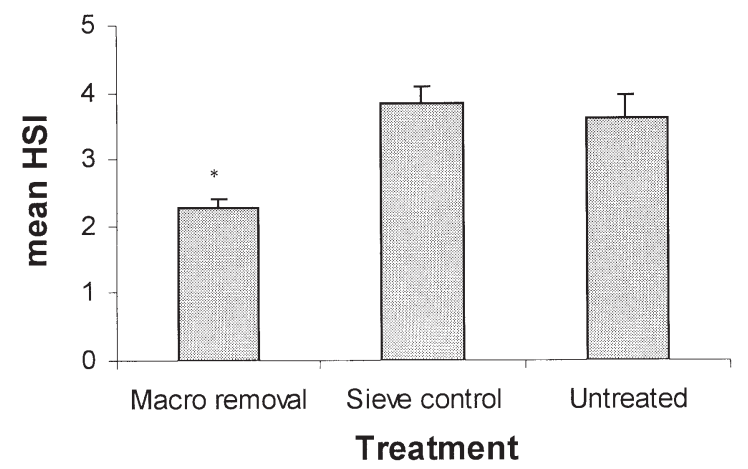

Fig. 2. Pomatoschistus microps. Consequence of macrofaunal prey depletion on mean male goby HSI $(+\mathrm{SE})$. Fish from treatments without macro-fauna had significantly lower HSI (ANOVA, $\mathrm{p}<0.01$ ) biomass (AFDW; $F_{1,12}=0.28, \mathrm{p}>0.05, F_{2,2}=0.21, \mathrm{p}>$ 0.05, respectively; Fig. 1b). In addition, mean meiofauna abundance did not change over the duration of the experiments $\left(t_{0.05,24}=-1.39, \mathrm{p}>0.05\right)$. Corophium, the principal macrofaunal prey of common gobies in the Gullmar Fjord (Edlund \& Magnhagen 1981, Pihl 1985, Magnhagen 1986), differed significantly in abundance between treatments $\left(F_{2,18}=36.26, \mathrm{p}<\right.$ $0.001)$ but not date $\left(F_{1,18}=0.00, \mathrm{p}>0.05\right)$. Results for Corophium biomass were almost identical. The 'macrofauna removal' sediment had the lowest and 'untreated' sediment the highest Corophium abundances. Post hoc pair-wise comparisons (SNK test) revealed significant differences between all treatments (Fig. 1a). Fig. 1b shows how the AFDW attributable to Corophium compares with that for other macrofauna and also for meiofaunal prey.

\section{Fish condition measures}

There was no significant difference in the size or condition factor of fish between dates or treatments. However, fish maintained on 'macrofauna removal' sediment treatment had a significantly lower HSI than fish in control treatments (Fig. 2, Table 1). Fish in the second experiment also had significantly lower HSI than those in the first (Table 1).

\section{Measurement of nest building}

The roof:no roof ratio in the non-experimental fish was 3:1 (i.e. the probability of the nest roof being covered was 0.75) and was used as the 'expected' value. Fish from the 'macrofauna removal' treatment exhibited significantly lower nest building activity compared 


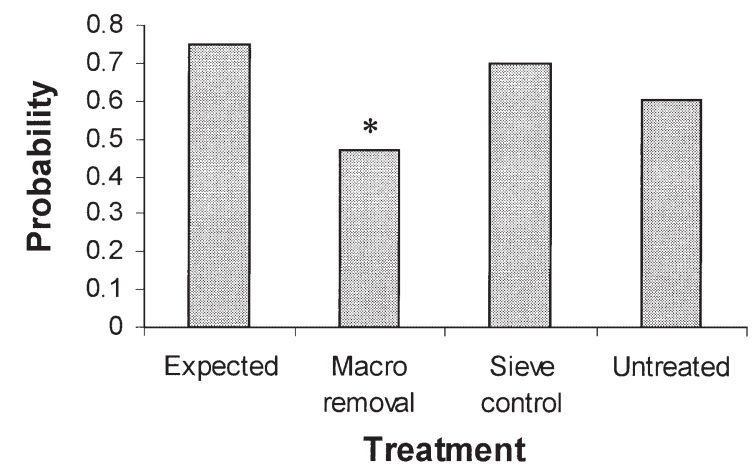

Fig. 3. Pomatoschistus microps. Consequence of macrofaunal prey depletion on likelihood of nest coverage compared to non-experimental fish. Fish maintained without macrofauna (*) were less likely to cover their nest with sediment (exact binomial probability, $\mathrm{p}=0.009$ )

with this reference $(p=0.009)$, but neither of the treatments containing macrofauna differed from reference fish (Fig. 3). There was no significant difference in nest entrance diameter between dates $\left(F_{1,18}=1.10, p>0.05\right)$ or treatments $\left(F_{2,2}=0.20, \mathrm{p}>0.05\right)$.

\section{Nest quality determinants}

For individual fish, probability of roof covering was not related to length $\left(t_{0.05,52}=1.63, \mathrm{p}>0.05\right)$ and there was no significant correlation between length and entrance diameter. Condition factor was not correlated with any measure of nest building activity; however, there was a significant difference in HSI between fish that covered roofs and those which did not $\left(t_{0.05,52}=\right.$ 2.85, p < 0.01) (Fig. 4). A significant negative relationship also existed between HSI and entrance diameter although variability was high $\left(\mathrm{r}^{2}=0.21, \mathrm{p}<0.001\right)$.

\section{DISCUSSION}

The depletion of macrofaunal prey resources had clear effects on male common gobies, leading to significantly lower HSI and nest building when maintained in treatments with macrofauna removed compared with those containing macrofaunal prey (Figs. $2 \& 3$ ). In addition, HSI and nest quality were strongly linked (Fig. 4). Together, these results demonstrate a strong negative effect of macrofaunal prey depletion on fish condition and reproduction, as gauged by nest building activity. The implications for field populations may be considerable; the common goby is short-lived, breeding repeatedly through the summer before dying in its second winter (Miller 1975). Loss of condition in years where macrofaunal recruitment fails may not only increase disease and starvation (Smith \& Wooton 1995) but also affect current and future reproductive success. Pihl \& Rosenberg (1982) have previously shown that recruitment of common gobies can be highly variable, and it may be that such variation is a consequence of prey depletion.

Male parental care involves construction and maintenance of a nest, and the care of the eggs until hatching (Magnhagen 1992). Here, prey availability clearly had an effect on the males' ability to construct nests (Fig. 3), a lack of macrofaunal prey reducing the likelihood that high-quality nests will be constructed when compared to non-experimental fish. Two important characteristics in nest construction are susceptibility to predation and ease of ventilation. High-quality nests, with complete sediment coverage, are more cryptic and less susceptible to egg (e.g. Carcinus maenas) or aerial predators, resulting in greater-average hatching success (Jones \& Reynolds 1999). Similarly, sediment around the front of the nest will determine entrance size, a further component of nest crypsis. Males may consequently build nests with entrances as small as they are capable of ventilating successfully with no reduction in hatching success (Jones \& Reynolds 1999). Females preferentially choose males with smaller nest entrances (Jones \& Reynolds 1999). Nest construction is thus a product of both natural and sexual selection and, as such, is a direct measure of male fitness. The absence of differences in nest entrance diameter between treatments and a weak correlation with HSI perhaps indicates that entrance diameter is a less sensitive measure of male quality than roof cover. Nest entrance diameter was observed to vary with time as the fish moved in and out of the nest, so its utility as a measure of fitness may be questionable.

The clear effect of prey resource depletion on both HSI and nest quality bolsters Kvarnemo et al.'s (1998) assertion that nest quality may be an indicator of fish condition and suggests a potential causal link with food availability as a determining factor in nest con-

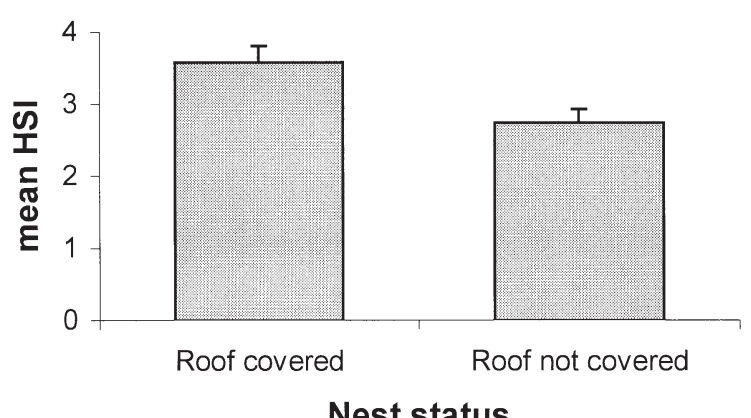

Fig. 4. Pomatoschistus microps. Mean HSI (+SE) of male gobies that covered their nest with sediment and those that did not. Nest coverers had a significantly greater HSI $(t$-test, $p<0.01)$ 
struction ability. The failure of the condition factor, $k$, to mirror these patterns may be further support for the utility of HSI as a sensitive measure of fish condition as a consequence of varying resource availability.

We suggest that initial prey abundance in sediment with macrofauna was sufficient to maintain fish condition over the $2 \mathrm{wk}$ period, i.e. macrofaunal food was in excess. The significant reduction in HSI between the 2 start dates (Table 1) may be a consequence of males in the second experiment, which started $3 \mathrm{wk}$ after the first, having expended more energy in breeding. Since males are tied to the nest during courting, mating and egg development, feeding opportunities are reduced (Magnhagen 1986), potentially leading to reduced condition.

The loss of condition and subsequent influence on nest building and fitness may have arisen from 1 or a combination of reasons. Firstly, males gobies may simply have been unable to forage on meiofauna due to an irreversible switch to macrofaunal prey. This seems unlikely, however, as meiofauna were found in the stomach contents of fish removed from the experiment and in similar-sized fish from the natural environment. Secondly, removal of macrofauna may have drastically reduced total prey biomass, with the remaining meiofaunal biomass insufficient for the energy requirements of male common gobies in this size range. The biomass contributed by meiofaunal prey was ca. $10 \%$ that of Corophium (Fig. 1b), suggesting this might be a possibility. However, meiofaunal abundance was not significantly lower in macrofauna removal treatments at the end of the experiment, which might be predicted if these prey were a limited resource. Thirdly, gobies may have switched to meiofaunal prey, with associated costs in this plasticity in feeding behaviour (Ebenman 1992, Komers 1997) contributing to the loss of condition, e.g. through increased search and handling times for a lower energetic return. It seems likely that this is the most likely explanation for the reduction of condition in common gobies, and further investigation of this mechanism would be profitable.

In conclusion, a manipulated depletion of macrofaunal prey resources appears to have caused a reversion in mature male common gobies to feeding on meiofauna, indicating a degree of plasticity in foraging behaviour. This depletion had serious consequences for the gobies, manifested here in terms of reduced hepatosomatic condition and nest building ability. Such reductions in the individual fitness of the most abundant benthic-feeding fish in shallow marine systems are also likely to have marked consequences and implications at the population and assemblage level.
Acknowledgements. The study was supported by a grant from the European Commission Access to Research Infrastructures (ARI) scheme. Experimental work was carried out at KMRS under the Fisheries Board Order No. 103-61-01. Particular thanks are owed to Prof. Leif Pihl for loan of his equipment and facilities, and to Dr. Elisabet Forsgren for lending us tanks and flowerpots. Thanks also to all our colleagues at KMRS for assistance during the summer.

\section{LITERATURE CITED}

Aarnio K (2001) The role of meiofauna in benthic food webs of the northern Baltic Sea. PhD thesis, Åbo Akademi University, Åbo

Bodiou JY, Villiers L (1979) La prédation de la méiofaune par les formes juvéniles de Deltentosteus quadrimaculatus (Telesostei, Gobiidae). Vie Milieu 28/29:143-156

Del Norte-Campos AGC, Temming A (1994) Daily activity, feeding and rations in gobies and brown shrimp in the northern Wadden Sea. Mar Ecol Prog Ser 115:41-53

Doornbos G, Twisk F (1987) Density, growth and annual food consumption of gobiid fish in the saline lake Grevelingen, the Netherlands. Neth J Sea Res 21:45-74

Ebenman B (1992) Evolution in organisms that change their niches during their life cycle. Am Nat 139:990-1021

Edlund AM, Magnhagen C (1981) Food segregation and consumption suppression in two coexisting fishes, Pomatoschistus minutus and P. microps: an experimental demonstration of competition. Oikos 36:23-27

Evans S (1984) Energy budgets and predation impact of dominant epibenthic carnivores on a shallow soft-bottom community at the Swedish west coast. Estuar Coast Shelf Sci 18:651-672

Grossman GD (1980) Ecological aspects of ontogenetic shifts in prey size utilisation in the bay goby (Pisces: Gobiidae). Oecologia 47:233-238

Hjelm J, Persson L, Christensen B (2000) Growth, morphological variation and ontogenetic niche shifts in perch (Perca fluviatilis) in relation to resource availability. Oecologia 122:190-199

Holme NA, MacIntyre AD (1984) Methods for the study of marine benthos. Blackwell Scientific Publications, Oxford

Ivlev VA (1961) Experimental ecology of the feeding of fishes. Yale University Press, New Haven, CT

Jensen KT, Andre C (1993) Field and laboratory experiments on interactions among an infaunal polychaete, Nereis diversicolor, and two amphipods, Corophium volutator and $C$. arenarium: effects on survival, recruitment and migration. J Exp Mar Biol Ecol 168:259-278

Jones JC, Reynolds JD (1999) The influence of oxygen stress on female choice for male nest structure in the common goby. Anim Behav 57:189-196

Komers PE (1997) Behavioural plasticity in variable environments. Can J Zool 75:161-169

Kvarnemo C, Svensson O, Forsgren E (1998) Parental behaviour in relation to food availability in the common goby. Anim Behav 56:1285-1290

Magnhagen C (1986) Activity differences influencing food selection in the marine fish Pomatoschistus microps. Can J Fish Aquat Sci 43:223-227

Magnhagen C (1988) Changes in foraging as a response to predation risk in 2 gobiid fish species, Pomatoschistus minutus and Gobius niger. Mar Ecol Prog Ser 49:21-26

Magnhagen C (1992) Alternative reproductive behaviour in the common goby, Pomatoschistus microps: an ontogenetic gradient. Anim Behav 44:182-184 
Magnhagen C, Wiederholm AM (1982a) Food selectivity versus prey availability: a study using the marine fish Pomatoschistus microps. Oecologia 55:311-315

Magnhagen C, Wiederholm AM (1982b) Habitat and food preferences of Pomatoschistus minutus and P. microps (Gobiidae) when alone and together: an experimental study. Oikos 39:152-156

Miller PJ (1975) Age-structure and life-span in the common goby, Pomatoschistus microps. J Zool 177:425-448

Miller PJ (1986) Gobiidae. In: Whitehead PJP, Bauchot ML, Hureau JC, Nielsen J, Tortonese E (eds) Fishes of the north-eastern Atlantic and the Mediterranean, Vol 3. UNESCO, Paris, p 1019-1085

Möller P, Rosenberg R (1982) Production and abundance of the amphipod Corophium volutator in some marine habitats on the west coast of Sweden. Neth J Sea Res 16:127-140

Olson MH (1996) Ontogenetic niche shifts in largemouth bass: variability and consequences for first year growth. Ecol 77:179-190

Persson L (1990) Predicting ontogenetic niche shifts in the field: what can be gained by foraging theory? In: Hughes RN (ed) Behavioural mechanisms of food selection. Springer-Verlag, Berlin

Pihl L (1985) Food selection and consumption of mobile

Editorial responsibility: Otto Kinne (Editor),

Oldendorf/Luhe, Germany epibenthic fauna in shallow marine areas. Mar Ecol Prog Ser 22:169-179

Pihl L, Rosenberg R (1982) Production, abundance and biomass of mobile epibenthic marine fauna in shallow waters, western Sweden. J Exp Mar Biol Ecol 57:273-301

Schoener TW (1971) Theory of feeding strategies. Annu Rev Ecol Syst 2:369-404

Smith C, Wooton RJ (1995) The cost of parental care in teleost fishes. Rev Fish Biol Fish 5:7-22

Sokal RR, Rohlf J (1995) Biometry: the principles and practice of statistics in biological research. WH Freeman, New York

Somerfield PJ, Warwick RM (1996) Meiofauna in marine pollution monitoring programmes: a laboratory manual. Ministry of Agriculture, Fisheries and Food, Lowestoft

Stephens DW, Krebs JR (1986) Foraging theory. Princeton University Press, Princeton, NJ

Warwick RM (1984) Species size distributions in marine benthic communities. Oecologia 61:32-41

Weatherley AH (1972) Growth and ecology of fish populations. Academic Press, London

Werner EE, Gilliam JF (1984) The ontogenetic niche and species interactions in size-structured populations. Annu Rev Ecol Syst 15:393-425

Submitted: April 4, 2002; Accepted: July 23, 2002

Proofs received from author(s): September 25, 2002 